Supporting Information

\title{
Cradle-to-Gate Emissions from a Commercial Electric Vehicle Li-Ion Battery: A Comparative Analysis
}

\author{
Hyung Chul Kim, Timothy J. Wallington, Renata Arsenault, Chulheung Bae, Suckwon Ahn, Jaeran Lee
}

Supporting Information includes:

Figure S1: Breakdown of Focus BEV battery based on Component

Figure S2: Comparison of Cradle-to-gate GHG emissions of cell only

Table S1: Detailed Cradle-to-gate emissions from Focus BEV battery

Table S2: Comparison of GHG emissions estimates across studies 


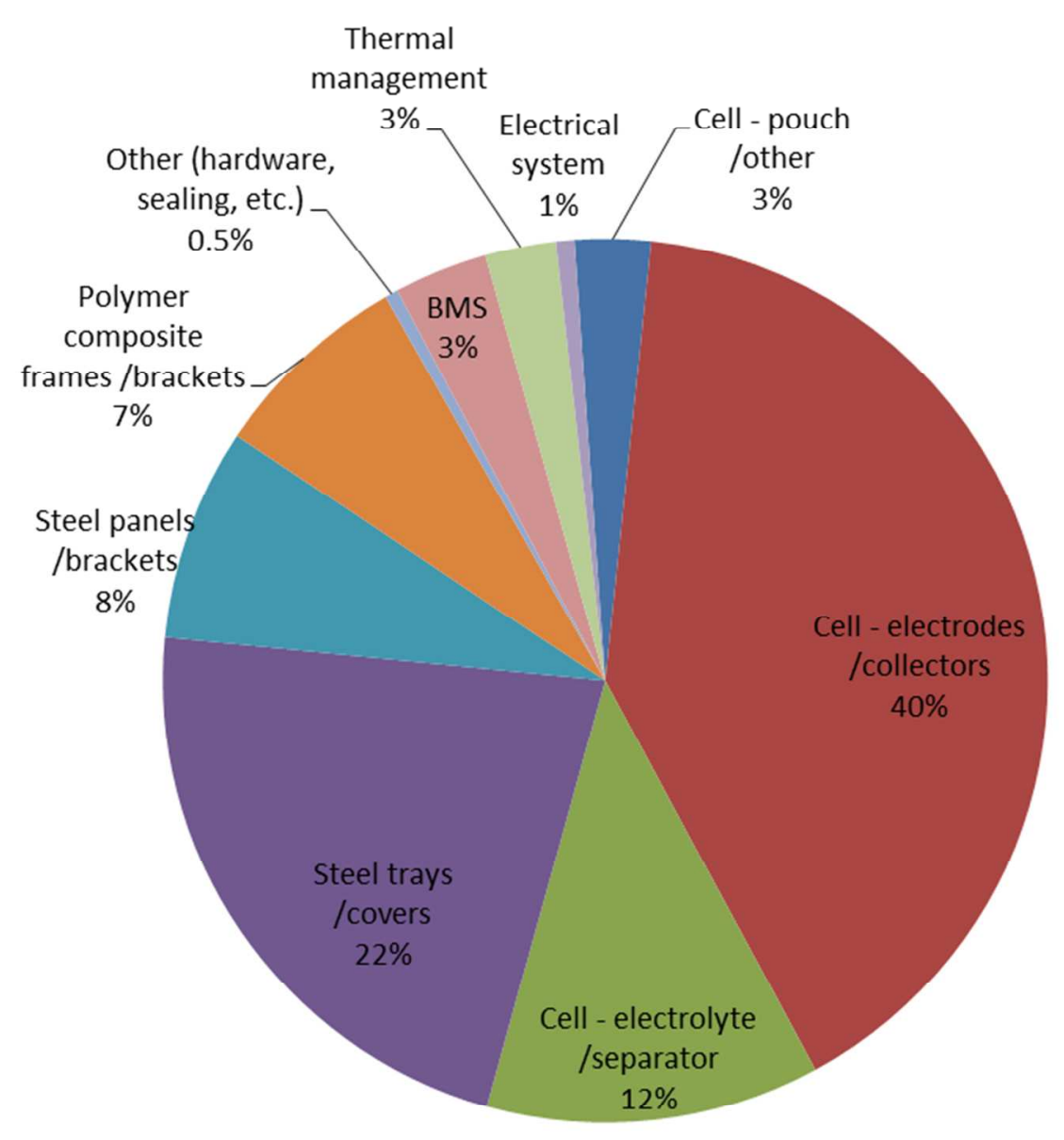

Figure S1: Breakdown of Focus BEV battery based on Component 


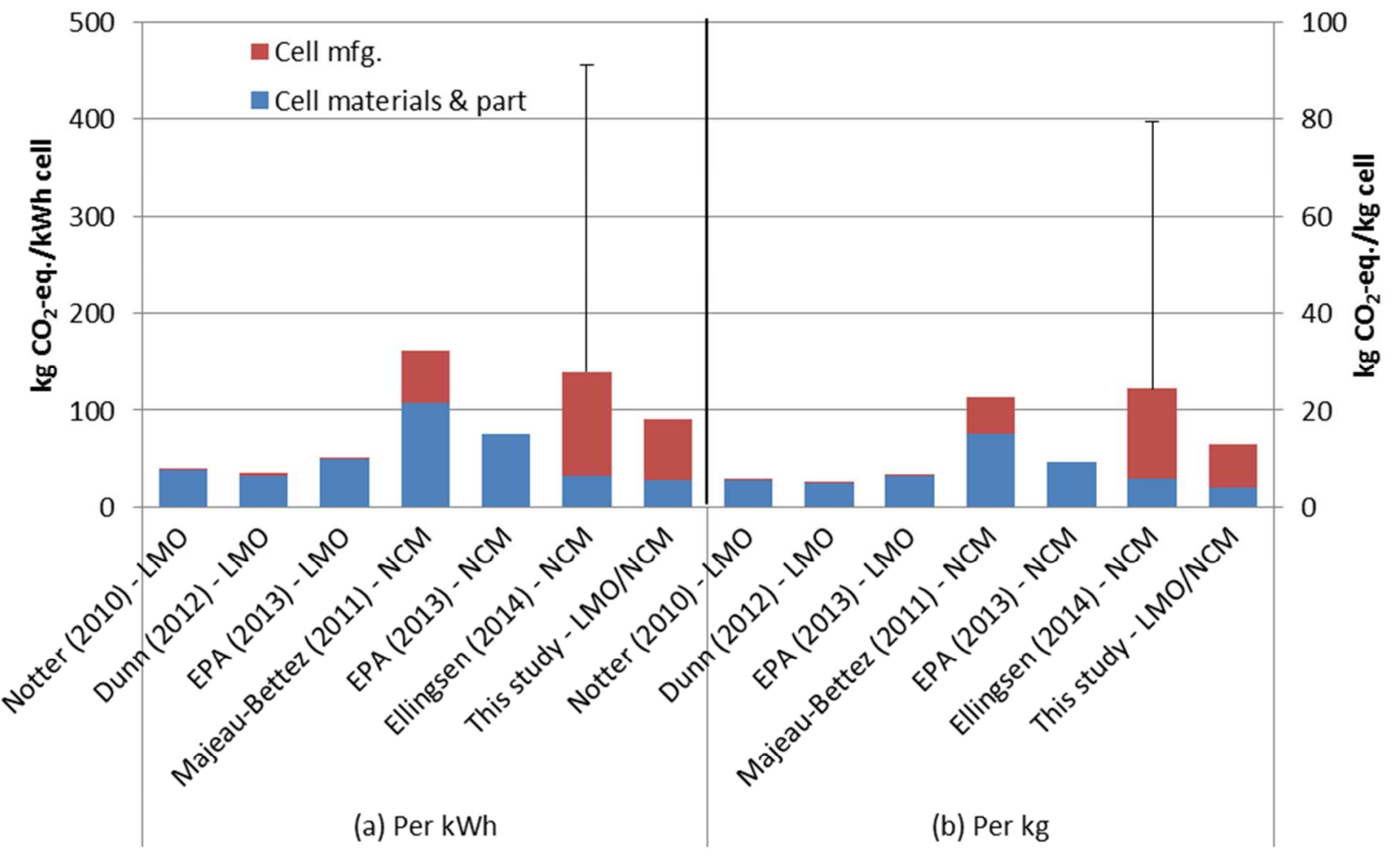

Figure S2: Comparison of Cradle-to-gate GHG emissions of cell only 
Table S1: Detailed Cradle-to-gate emissions from Focus BEV battery

\begin{tabular}{|c|c|c|c|c|c|c|c|c|c|c|c|c|}
\hline Functional unit & & & $1 \mathrm{kWh}$ & attery & & & & & $1 \mathrm{~kg} \mathrm{k}$ & tery & & \\
\hline Pollutant & $\begin{array}{l}\text { GHG (kg } \\
\mathrm{CO}_{2} \text { - eq.) }\end{array}$ & VOC (g) & $\mathrm{CO}(\mathrm{g})$ & $\mathrm{NO}_{x}(\mathrm{~g})$ & PM (g) & $\mathrm{SO}_{x}(\mathrm{~g})$ & $\begin{array}{l}\mathrm{GHG} \text { (kg } \\
\mathrm{CO}_{2} \text { - eq.) }\end{array}$ & VOC (g) & $\mathrm{CO}(\mathrm{g})$ & $\mathrm{NO}_{x}(\mathrm{~g})$ & PM (g) & $\mathrm{SO}_{\mathrm{x}}(\mathrm{g})$ \\
\hline Cell materials & 27 & 43 & 102 & 96 & 62 & 845 & 2.2 & 3.4 & 8.2 & 7.7 & 4.9 & 67.6 \\
\hline $\begin{array}{l}\text { Cell } \\
\text { manufacturing }\end{array}$ & 63 & 10 & 17 & 182 & 12 & 185 & 5.0 & 0.8 & 1.3 & 14.6 & 1.0 & 14.8 \\
\hline Enclosure & 25 & 24 & 185 & 57 & 80 & 86 & 2.0 & 1.9 & 14.8 & 4.5 & 6.4 & 6.8 \\
\hline $\begin{array}{l}\text { Thermal } \\
\text { Management }\end{array}$ & 5.9 & 1.5 & 39 & 11 & 11 & 22 & 0.5 & 0.1 & 3.2 & 0.9 & 0.9 & 1.7 \\
\hline Electrical System & 0.5 & 1.2 & 2.1 & 5.9 & 6.0 & 27 & 0.04 & 0.1 & 0.2 & 0.5 & 0.5 & 2.2 \\
\hline BMS & 13 & 1.6 & 5.3 & 15 & 5.0 & 25 & 1.0 & 0.1 & 0.4 & 1.2 & 0.4 & 2.0 \\
\hline $\begin{array}{l}\text { Pack } \\
\text { manufacturing }\end{array}$ & 1.7 & 0.2 & 0.7 & 3.2 & 1.5 & 8.8 & 0.1 & 0.02 & 0.1 & 0.3 & 0.1 & 0.7 \\
\hline Transportation & 4.1 & 6.5 & 9.2 & 34 & 3.3 & 18 & 0.3 & 0.5 & 0.7 & 2.7 & 0.3 & 1.5 \\
\hline Total & 141 & 87 & 360 & 404 & 181 & 1282 & 11.3 & 7.0 & 28.8 & 32.3 & 14.5 & 97.4 \\
\hline
\end{tabular}


Table S2: Comparison of GHG emissions estimates across studies

\begin{tabular}{|c|c|c|c|c|c|c|c|c|c|c|c|c|c|c|}
\hline \multirow[t]{3}{*}{ Reference } & \multirow[t]{3}{*}{$\begin{array}{l}\text { Battery } \\
\text { type }\end{array}$} & \multirow{2}{*}{\multicolumn{2}{|c|}{ Mass (kg) }} & \multirow{3}{*}{\begin{tabular}{|l} 
Total \\
energy \\
(kWh)
\end{tabular}} & \multirow{2}{*}{\multicolumn{2}{|c|}{$\begin{array}{l}\text { Specific energy } \\
(\mathrm{kWh} / \mathrm{kg})\end{array}$}} & \multicolumn{4}{|c|}{$\begin{array}{l}\text { GHG emissions (primary energy) from } \\
\text { cradle-to-gate of battery }\end{array}$} & \multicolumn{4}{|c|}{$\begin{array}{l}\text { GHG emissions from cradle-to-gate } \\
\text { of cell }\end{array}$} \\
\hline & & & & & & & \multicolumn{2}{|c|}{$\begin{array}{l}\mathrm{kg} \mathrm{CO} \text {-eq./kg battery } \\
\left(\mathrm{MJ}_{\mathrm{p}} / \mathrm{kg} \text { battery) }\right.\end{array}$} & \multicolumn{2}{|c|}{$\begin{array}{l}\mathrm{kg} \mathrm{CO} \text {-eq./kWh } \\
\text { battery }\end{array}$} & \multicolumn{2}{|c|}{ kg CO 2 -eq./kg cell } & \multicolumn{2}{|c|}{$\begin{array}{l}\mathrm{kg} \mathrm{CO} \text {-eq./kWh } \\
\text { cell }\end{array}$} \\
\hline & & Battery & Cell & & Battery & Cell & $\begin{array}{l}\text { Materials } \\
\text { /parts }\end{array}$ & $\begin{array}{l}\text { Cell /pack } \\
\mathrm{mfg} \text {. }\end{array}$ & $\begin{array}{l}\text { Materials } \\
\text { /parts }\end{array}$ & $\begin{array}{l}\text { Cell } \\
\text { /pack } \\
\text { mfg. }\end{array}$ & $\begin{array}{l}\text { Materials } \\
\text { /parts }\end{array}$ & $\begin{array}{l}\text { Cell } \\
\mathrm{mfg} .\end{array}$ & $\begin{array}{l}\text { Materials } \\
\text { /parts }\end{array}$ & $\begin{array}{l}\text { Cell } \\
\text { mfg. }\end{array}$ \\
\hline $\begin{array}{l}\text { Notter et al. } \\
(2010)^{1}\end{array}$ & LMO & 300 & 240 & 34.2 & 0.114 & 0.14 & 5.8 & $0.16(2.4)$ & 51 & 1.4 & 5.5 & 0.13 & 39 & 0.88 \\
\hline $\begin{array}{l}\text { Dunn et al. } \\
(2012)^{2} ; \text { GREET } \\
(2015)^{3}\end{array}$ & LMO & 210 & $190^{a}$ & 28 & 0.13 & 0.15 & 4.9 & 0.27 (3.9) & 37 & 2.1 & 4.8 & 0.3 & 33 & 2.0 \\
\hline EPA $(2013)^{4}$ & LMO & na & $\begin{array}{l}80 \%{ }^{\mathrm{b}} \text { of } \\
\text { battery }\end{array}$ & na & $\begin{array}{l}0.08- \\
0.1\end{array}$ & \begin{tabular}{|l|}
$0.1-$ \\
0.125
\end{tabular} & 6.2 & $0.18(2.9)$ & 62 & 1.8 & 6.3 & 0.22 & 50 & 1.8 \\
\hline $\begin{array}{l}\text { Majeau-Bettez } \\
\text { et al. }(2011)^{5} ; \\
\text { Hawkins et al. } \\
(2013)^{6}\end{array}$ & NCM & 214 & 171 & 24 & 0.112 & 0.14 & 16.0 & $\begin{array}{l}6.0(80- \\
105)^{\mathrm{c}}\end{array}$ & 143 & 54 & 15.1 & 7.5 & 108 & 54 \\
\hline EPA $(2013)^{4}$ & NCM & na & $\begin{array}{l}80 \%{ }^{\mathrm{b}} \text { of } \\
\text { battery }\end{array}$ & na & $\begin{array}{l}0.08- \\
0.1\end{array}$ & \begin{tabular}{|l|}
$0.1-$ \\
0.125 \\
\end{tabular} & 8.7 & $3.4(62.1)$ & 87 & 34 & 9.4 & 0 & 76 & 0 \\
\hline $\begin{array}{l}\text { Ellingsen et al. } \\
(2014)^{7}\end{array}$ & NCM & 253 & 152 & 26.6 & 0.11 & 0.17 & 6.9 & $\begin{array}{l}\text { d } 11.3(180) ; \\
\text { e } 18.5(300) ; \\
\text { f } 44.5(730)\end{array}$ & 65 & $\begin{array}{l}108 ; \\
176 ; \\
425\end{array}$ & 5.7 & $\begin{array}{l}18.7 \\
30.6 \\
73.9\end{array}$ & 33 & $\begin{array}{l}107 ; \\
175 ; \\
424\end{array}$ \\
\hline This study & $\begin{array}{l}\text { LMO } \\
\text { /NCM }\end{array}$ & 303 & 168 & 24 & 0.08 & 0.14 & 6.1 & $5.2(120)$ & 76 & 65 & 4.0 & 9.1 & 28 & 64 \\
\hline
\end{tabular}

${ }^{a}$ estimated based on materials breakdown; ${ }^{b}$ average value of the range in EPA (2013); ${ }^{c}$ estimated from the direct energy inputs in Ellingsen et al. $(2014)^{7}, 371-473 \mathrm{MJ} / \mathrm{kWh}$, based on an electric and fossil energy share of $51.7 \%$ and $48.3 \%$ respectively and a primary energy to electricity conversion factor of 0.35 as in Majeau-Bettez et al. $(2011)^{5} ;^{d}$ lower bound value; ${ }^{e}$ asymptotic value; ${ }^{f}$ average value ${ }^{7}$ 


\section{References}

(1) Notter, D. A.; Gauch, M.; Widmer, R.; Wagner, P.; Stamp, A.; Zah, R.; Althaus, H.-J. Contribution of Li-Ion Batteries to the Environmental Impact of Electric Vehicles. Environ. Sci. Technol. 2010, 44, 6550-6556.

(2) Dunn, J. B.; Gaines, L.; Sullivan, J.; Wang, M. Q. Impact of Recycling on Cradle-to-Gate Energy Consumption and Greenhouse Gas Emissions of Automotive Lithium-Ion Batteries. Environ. Sci. Technol. 2012, 46, 12704-12710.

(3) Argonne National Laboratory (ANL) GREET Model. Transportation Research and Analysis Computing Center, Argonne National Laboratory. Argonne, IL 2015.

(4) US EPA Application of Life-Cycle Assessment to Nanoscale Technology: Lithium-ion Batteries for Electric Vehicles; EPA 744-R-12-001; 2013.

(5) Majeau-Bettez, G.; Hawkins, T. R.; Strømman, A. H. Life Cycle Environmental Assessment of Lithium-lon and Nickel Metal Hydride Batteries for Plug-In Hybrid and Battery Electric Vehicles. Environ. Sci. Technol. 2011, 45, 4548-4554.

(6) Hawkins, T. R.; Singh, B.; Majeau-Bettez, G.; Strømman, A. H. Comparative Environmental Life Cycle Assessment of Conventional and Electric Vehicles. J. Ind. Ecol. 2013, 17, 53-64.

(7) Ellingsen, L. A.-W.; Majeau-Bettez, G.; Bhawna Singh; Srivastava, A. K.; Valøen, L. O.; Strømman, A. H. Life Cycle Assessment of a Lithium-Ion Battery Vehicle Pack. J. Ind. Ecol. 2014, 18 (1), 113-124. 